\title{
Effects of Makeup, Perfume and Skincare Product Usage and Hair Care Regimen on Circadian Typology, Sleep Habits and Mental Health in Female Japanese Students Aged 18 - 30*
}

\author{
Risa Nishihara ${ }^{1}$, Kai Wada ${ }^{1}$, Osami Akimitsu ${ }^{1}$, Milada Krejci ${ }^{2}$, Teruki Noji ${ }^{3}$, \\ Miyo Nakade ${ }^{4}$, HitomiTakeuchi ${ }^{1}$, Tetsuo Harada ${ }^{\text {i\# }}$ \\ ${ }^{1}$ Department Laboratory of Environmental Physiology, Graduate School of Integrated Arts and Sciences, \\ Kochi University, Kochi, Japan \\ ${ }^{2}$ Department of Health Education, Faculty of Education, University of South Bohemia, Ceske Budejovice, \\ Czech Republic \\ ${ }^{3}$ Department of Physical Education, Faculty of Education, Kochi University, Kochi, Japan \\ ${ }^{4}$ Department of Nutritional Management, Faculty of Health and Nutrition, Tokai Gakuen University, \\ Nagoya, Japan \\ Email: "haratets@kochi-u.ac.jp, gg02@kochi-u.ac.jp, spitz_czech@yahoo.co.jp,b10m6b07@s.kochi-u.ac.jp, \\ krejci@pf.jcu.cz,noji@kochi-u.ac.jp, nakade34@go.enjoy.ne.jp, rhythmsyn@hotmail.co.jp
}

Received September $8^{\text {th }}, 2012$; revised January $11^{\text {th }}, 2013$; accepted February $9^{\text {th }}, 2013$

\begin{abstract}
Olfactory stimulation has been reported to trigger waking up during night sleep, and to affect the sympathetic nervous system and blood pressure of humans via the circadian clock system. Olfactory stimulation may promote better sleep health in Japanese students living in 24-hour society, but no studies have been done on this hypothesis. The purpose of this study is to make it clear what are the effects of makeup, perfume and skin care products on the circadian typology, sleep habits and mental health of female Japanese students aged 18 - 30 using an integrated questionnaire. Students who regularly used skin care products went to bed earlier on both weekdays and weekends and also got up earlier in the morning on weekdays than those who did not $(p<0.05)$. The students who wore makeup two or more days per week showed higher sleep quality than those who were makeup only one day a week or less $(p<0.05)$. The students who regularly carried out a hair care regimen showed a significantly lower frequency of becoming angry after a small trigger and of losing control due to anger than those who did not. Makeup, perfume and skin care products might be possible to be related to better sleep health for students. Moreover, hair care may help maintain mental health in female students. Makeup, perfume and skin care products might be implied to become chemical, mechanical and/or psychological stimuli as zeitgebers for circadian clock of students.
\end{abstract}

Keywords: Makeup; Perfume; Skin Care; Circadian Typology; Sleep Health; Mental Health; Japanese Students Aged 18 - 30 yrs

\section{Introduction}

Olfactory stimulation triggers waking up during night sleep (Borio, 2006), and affects the sympathetic nervous system and blood pressure of humans via the circadian clock system (Nagai, 2007). Olfactory stimulation may promote better sleep health in Japanese students living in 24-hour society. A hypothesis might be available that stimulation by olfactory chemicals at regular time including make-up products, perfume and skin-care products and also hair-care regime could become chemical, mechanical and/or psychological zeitgebers. The progression of 24-hour commercialization society disturbs diurnal rhythms in both young and older Japanese students (Harada, 2008). The olfactory zeitgebers might diminish the disturbance of diurnal rhythms due to the 24-hour commercialization society

Many studies have been done on the effects of makeup behaviour on psychological feature exclusively (Kato et al., 2010).

\footnotetext{
"The authors declare that they have no competing interests.

\#Corresponding author.
}

However, only a limited number of studies have been carried out on the effects of makeup and perfume and olfactory stimulations on circadian typology and sleep in humans. Goel and Lao (2006) showed that peppermint, a stimulating odor, increased non-rapid eye movement (NREM) sleep in women and increased alertness in men. Sandalwood oil has been widely used in aromatherapy for alleviating various symptoms. Application of santalol, a major component of sandalwood oil, caused a significant decrease in total waking time and an increase in total NREM sleep time in rats (Ohmori et al., 2007). Komori et al. (1997) showed that a mixed odorant (Central Nervous System stimulant) consisting of rose, sandalwood and iris increased sleep time by $37 \%$ in male Sprague-Dawley rats, while lemon (CNS depressant) decreased it by $23 \%$.

This study attempts to clarify the effects of using makeup, perfume and skincare products and carrying out a hair care regimen on the circadian typology, sleep habits and mental health and tries to answer the question, "whether can the olfactory, mechanical and/or psychological stimulants become the 
significant zeitgeber for women?", from an epidemiological point of view.

\section{Participants and Methods}

\section{Procedure of the Questionnaire Study}

This cross-sectional study was conducted in October 2010, using an integrated questionnaire which was administered to 166 female students aged 18 - 30 who attended a university (126) or a training school for nurses (40), both located in Kochi Prefecture in Japan $\left(33^{\circ} \mathrm{N}\right)$. The female participants were randomly sampled from a wide majoring field (Faculties of Education, Science, Humans and Literatures, Agriculture, Medical School and Nurses Training School). Responses were received from 166 students (response rate of 100\%) and incomplete responses (i.e. age was not filled out or the diurnal preference section was incomplete) were discarded. Analysis for the current study was then limited to 161 responses from students aged $19-29$, in order to focus on young Japanese women. Classes in the university and the training school start at 8:50 and 8:40, respectively. Saturdays and Sundays are days off for both.

\section{Contents of the Questionnaire}

The integrated questionnaire consisted of three parts and asked participants to anonymously answer the questions on chronic state (subjective symptoms) of their life for the last month. The first part was a Japanese version for students (Harada, 2004a) of the Torsvall-Åkerstedt Diurnal type scale (1980). The diurnal type scale is used to measure an individual's diurnal preference. Three of the 7 questions included in the scale pertain to sleep onset timing in the evening, 3 to sleep offset timing in the morning, and 1 to peak timing of activity during the daytime. Each question allows for choice (scored from 1 to 4 ). The score of the scale is the sum of the 7 answers. The minimum possible score is 7 (extreme evening-type) and the maximum possible score is 28 (extreme morning-type).

The quality of sleep before the holidays or weekdays was expressed as a combined score of the frequency of difficulty falling asleep and waking up in the morning scored from 2 to 10 (2: both always, 10: both never).

The last part of the questionnaire consisted of original questions on use of makeup, perfume, and skincare products and application of a hair care regimen in their daily life. Table 1 shows the questions and possible answers.

\section{Reliability of the Integrated Questionnaire}

The questionnaire currently used most widely was constructed by Horne \& Östberg (1976) and was based on an original questionnaire by Östberg consisting of 14 items which was revised and lengthened to 19 items. Correlations have been examined in M-E scores in the two versions: one by Torsvall \& Åkerstedt (1980), the other by Horne \& Östberg (1976). High correlation values were shown by junior high students aged 11 15 years (Ishihara, communication, $r=0.673-0.762$; Pearson's correlation test: $p<0.001$ ), and for $18-25$ year old students in occupational and physical therapy training school (Harada unpublished, $\mathrm{r}=0.736$; Pearson's correlation test: $p<0.001)$. This provides validation of the Japanese version of the Torsvall \& Åkerstedt Diurnal Type Scale.
Table 1.

Questions and answers on using makeup (A), perfume (B) andskincare products $(\mathrm{C})$ and carrying out a hair care regimen (D).

\section{(A)}

\begin{tabular}{|c|c|}
\hline Q: & $\begin{array}{l}\text { Do you do wear makeup regularly? If yes, how many times } \\
\text { per week? }\end{array}$ \\
\hline A: & $\begin{array}{l}\text { Yes ((1) everyday, (2) } 4 \text { - } 5 \text { times, (3) } 2 \text { - } 3 \text { times, (4) } 0 \text { - } 1 \\
\text { time(s)), No }\end{array}$ \\
\hline \multicolumn{2}{|r|}{ (B) } \\
\hline Q: & $\begin{array}{l}\text { Do you wear perfume regularly? If yes, how many times per } \\
\text { week? }\end{array}$ \\
\hline A: & $\begin{array}{l}\text { Yes ((1) everyday, (2) } 4 \text { - } 5 \text { times, (3) } 2 \text { - } 3 \text { times, (4) } 0 \text { - } 1 \\
\text { time(s)), No }\end{array}$ \\
\hline \multicolumn{2}{|r|}{ (C) } \\
\hline Q: & $\begin{array}{l}\text { Do you use skincare products regularly (e.g. face or body } \\
\text { lotion)? If yes, how many times per week? }\end{array}$ \\
\hline A: & $\begin{array}{l}\text { Yes ((1) everyday, (2) } 4 \text { - } 5 \text { times, (3) } 2 \text { - } 3 \text { times, (4) } 0 \text { - } 1 \\
\text { time(s)), No }\end{array}$ \\
\hline \multicolumn{2}{|r|}{ (D) } \\
\hline Q: & $\begin{array}{l}\text { Do you regularly carry out a hair care regimen (e.g. using a } \\
\text { comb or using liquid, mousse, oil or gel)? If yes, how many } \\
\text { times per week? }\end{array}$ \\
\hline A: & $\begin{array}{l}\text { Yes ((1) everyday, (2) } 4 \text { - } 5 \text { times, (3) } 2 \text { - } 3 \text { times, (4) } 0 \text { - } 1 \\
\text { time(s)), No }\end{array}$ \\
\hline
\end{tabular}

Moreover, the Japanese version for students of the Torsvall-Åkerstedt Diurnal type scale questionnaire has been used in several papers (Takeuchi et al., 2001; Harada et al., 2002; Harada et al., 2006) and this version was again used in this study.

The sleep habits part of the integrated questionnaire used in this study was originally constructed by Harada et al. (1998) and has been used in several papers (Harada et al., 2002; Harada et al., 2004; Takeuchi et al., 2001; Takeuchi et al., 2003; Shinomiya et al., 2004; Harada et al., 2007; Nakade et al., 2009; Wada et al., 2009; Krejci et al., 2011).

\section{Statistical Analysis}

The questionnaire data was analyzed with $12.0 \mathrm{~J}$ statistical software for Windows (SPSS Inc., Chicago, IL, USA). MannWhitney U-test was used for pair wise comparative test of continuous numerals and Kai-square test was used for the categorized data. The independent variables are whether participants used or not the make-up products, perfume and skin-care products and hair-care regime, or the frequency to use these four products and regime, while dependent variables were the Diurnal Type Scale, variables on sleep duration and sleep quality, and variables on mental health. As the significant level for the statistical analyses, $5 \%$ was adopted in this study.

\section{Ethical Treatment}

This study followed the ethical guideline of the Journal of Physiological Anthropology for conducting research on human subjects. All the students attending a University or nurses training school who participated gave their consent. The committee in the Laboratory of Environmental Physiology, Graduate School of Integrated Arts and Sciences at Kochi University carried out an ethical inspection of the questionnaire and gave 


\section{R. NISHIHARA ET AL.}

permission to administer this epidemiological study to 18 to 30 years old students.

\section{Results}

Students who regularly wore perfume tended to wake up earlier on week day mornings (Table 2) and showed shorter sleep latency on weekends (Table 3) than those who did not. Students who regularly used skincare products went to bed earlier on both weekdays and the weekend and also got up earlier on weekday mornings than those who did not (Table 2). Students who wore makeup two or more days a week showed higher sleep quality than those who only wore makeup one day a week or less (Figure 1)

Students who used skincare products everyday included a higher proportion of participants that had difficulty waking up in the weekend morning than those who used skincare products less frequently (Table 4). Students who regularly used perfume included a higher ratio of participants who felt depression,

Table 2.

Relationship between whether participants use makeup, perfume, and skincare products and carry out a hair care regimen and circadian typology and sleep habits in Japanese female students (combined data of 161 university students and students in medical nurse training school) and statistical analysis (Kruskal-Wallis test). (Mean \pm SD [n]) WD: weekday; WE: weekend.

\begin{tabular}{|c|c|c|c|c|c|c|c|}
\hline & \multirow{2}{*}{ Diurnal score } & \multicolumn{2}{|c|}{ Bedtime } & \multicolumn{2}{|c|}{ Wakeup time } & \multicolumn{2}{|c|}{ Sleep duration } \\
\hline & & WD & WE & WD & WE & WD & WE \\
\hline \multicolumn{8}{|c|}{ Makeup } \\
\hline Yes & $15.8 \pm 3.4(127)$ & $24.2 \pm 1.1(129)$ & $25.0 \pm 1.3(129)$ & $7.0 \pm 1.2(129)$ & $9.3 \pm 1.7(129)$ & $6.8 \pm 1.3(128)$ & $8.3 \pm 1.6(128)$ \\
\hline No & $15.5 \pm 3.2(31)$ & $24.5 \pm 0.8(31)$ & $25.1 \pm 1.4(30)$ & $7.2 \pm 0.8(31)$ & $9.3 \pm 1.8(31)$ & $6.7 \pm 1.0(31)$ & $8.2 \pm .1 .1(30)$ \\
\hline \multicolumn{8}{|c|}{$U$-test } \\
\hline$Z$ & -0.323 & -1.495 & -0.256 & -1.287 & -0.188 & -0.223 & -0.328 \\
\hline$P$ & 0.746 & 0.135 & 0.798 & 0.198 & 0.851 & 0.823 & 0.743 \\
\hline \multirow{2}{*}{\multicolumn{2}{|c|}{ Diurnal score }} & \multicolumn{2}{|c|}{ Bedtime } & \multicolumn{2}{|c|}{ Wakeup time } & \multicolumn{2}{|c|}{ Sleep duration } \\
\hline & & WD & WE & WD & WE & WD & WE \\
\hline \multicolumn{8}{|c|}{ Perfume } \\
\hline Yes & $16.0 \pm 3.4(48)$ & $24.2 \pm 1.2(47)$ & $25.1 \pm 1.3(47)$ & $6.9 \pm 1.5(48)$ & $9.1 \pm 2.1(47)$ & $6.7 \pm 1.7(47)$ & $8.0 \pm 1.8(46)$ \\
\hline No & $15.6 \pm 3.3(111)$ & $24.4 \pm 1.0$ & $25.1 \pm 1.0(31)$ & $7.2 \pm 0.9(113)$ & $9.4 \pm 1.5(114)$ & $6.8 \pm 1.0(113)$ & $8.3 \pm 1.3(112)$ \\
\hline \multicolumn{8}{|c|}{$U$-test } \\
\hline$Z$ & -0.019 & -0.604 & -0.146 & -2.535 & -0.822 & -1.661 & -1.393 \\
\hline$P$ & 0.985 & 0.546 & 0.884 & $0.011^{*}$ & 0.411 & 0.097 & 0.164 \\
\hline & \multirow{2}{*}{ Diurnal score } & \multicolumn{2}{|c|}{ Bedtime } & \multicolumn{2}{|c|}{ Wakeup time } & \multicolumn{2}{|c|}{ Sleep duration } \\
\hline & & WD & WE & WD & WE & WD & WE \\
\hline \multicolumn{8}{|c|}{ Skin care products } \\
\hline Yes & $15.8 \pm 3.4(131)$ & $24.2 \pm 1.0(134)$ & $25.0 \pm 1.3(133)$ & $7.0 \pm 1.2(134)$ & $9.3 \pm 1.7(134)$ & $6.8 \pm 1.3(134)$ & $8.3 \pm 1.5(133)$ \\
\hline No & $14.7 \pm 3.0(20)$ & $24.9 \pm 0.9(20)$ & $25.6 \pm 1.1(18)$ & $7.7 \pm 0.7$ (19) & $10.0 \pm 1.4(20)$ & $6.8 \pm 0.9(19)$ & $8.1 \pm 1.0(18)$ \\
\hline \multicolumn{8}{|c|}{$U$-test } \\
\hline$Z$ & -1.487 & -3.044 & -2.049 & -2.649 & -1.740 & -0.315 & -0.602 \\
\hline$P$ & 0.137 & $0.002^{*}$ & $0.040^{*}$ & $0.008^{*}$ & 0.082 & 0.753 & 0.547 \\
\hline \multirow{2}{*}{\multicolumn{2}{|c|}{ Diurnal score }} & \multicolumn{2}{|c|}{ Bedtime } & \multicolumn{2}{|c|}{ Wakeup time } & \multicolumn{2}{|c|}{ Sleep duration } \\
\hline & & WD & WE & WD & WE & WD & WE \\
\hline \multicolumn{8}{|c|}{ Hair care regimen } \\
\hline Yes & $15.8 \pm 3.4(124)$ & $24.3 \pm 1.1(126)$ & $25.0 \pm 1.3(125)$ & $7.1 \pm 1.2(127)$ & $9.2 \pm 1.8(126)$ & $6.8 \pm 1.3(126)$ & $8.2 \pm 1.5(124)$ \\
\hline No & $15.9 \pm 3.0(32)$ & $24.3 \pm 0.8(32)$ & $25.1 \pm 1.0(31)$ & $7.1 \pm 0.9(31)$ & $9.6 \pm 1.5(32)$ & $6.8 \pm 0.8(31)$ & $8.4 \pm 1.2(31)$ \\
\hline \multicolumn{8}{|c|}{$U$-test } \\
\hline$Z$ & -0.331 & -0.334 & -0.503 & -0.446 & -1.243 & -0.011 & -0.503 \\
\hline$P$ & 0.741 & 0.738 & 0.615 & 0.656 & 0.214 & 0.991 & 0.615 \\
\hline
\end{tabular}




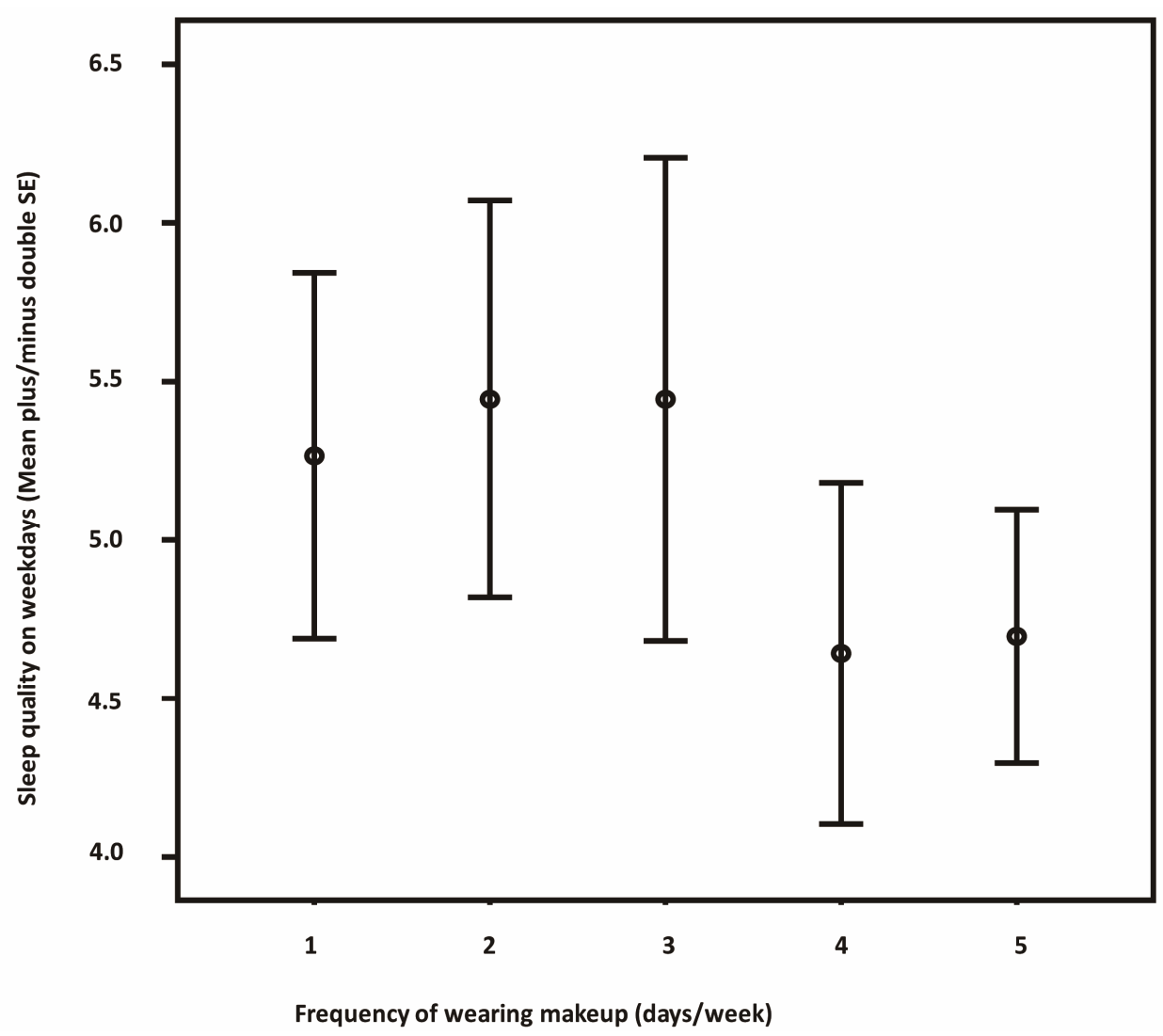

Figure 1.

Relationship between sleep quality and frequency of wearing makeup in female students aged 18 - 30 yrs. $\left(\chi^{2}\right.$-test: $\chi^{2}$-value $\left.=36.7, \mathrm{df}=4, \mathrm{p}=0.047\right)$.

Table 3.

Relationship between whether or not female students wear makeup and sleep latency on weekends, \% (n).

\begin{tabular}{|c|c|c|c|c|}
\hline \multirow[b]{2}{*}{ Makeup } & \multicolumn{4}{|c|}{ Sleep latency on weekends (min) } \\
\hline & $0-15$ & $16-30$ & $31-60$ & $>60$ \\
\hline Yes & $32.0(33)$ & $59.2(61)$ & $6.8(7)$ & $1.9(2)$ \\
\hline \multirow[t]{2}{*}{ No } & $36.2(21)$ & $39.7(23)$ & $19.0(11)$ & $5.1(3)$ \\
\hline & \multicolumn{3}{|c|}{$\chi^{2}$-test $: \chi^{2}$-value $=8.871, d f=3, p=0.031^{*}$} & \\
\hline
\end{tabular}

Table 4.

Relationship between frequency of using skincare product and frequency of having difficulty waking up in the morning on weekends, $\%$ (n).

\begin{tabular}{|c|c|c|c|c|c|}
\hline \multirow{2}{*}{ Frequency of skincareproduct usage } & \multicolumn{5}{|c|}{ Frequency of having difficulty waking up in the morning } \\
\hline & Always & Often & Sometime & Rare & Never \\
\hline Everyday & $47.7(55)$ & $32.8(38)$ & $14.7(17)$ & $5.2(6)$ & $0.0(0)$ \\
\hline $4-5$ times /week & $28.5(2)$ & $28.5(2)$ & $42.9(3)$ & $0.0(0)$ & $0.0(0)$ \\
\hline 2 - 3 times & $30.0(3)$ & $10.0(1)$ & $40.0(4)$ & $0.0(0)$ & $20.0(2)$ \\
\hline $0-1$ times & $0.0(0)$ & $50.0(2)$ & $50.0(2)$ & $0.0(0)$ & $0.0(0)$ \\
\hline Never & $27.3(3)$ & $36.4(8)$ & $27.3(6)$ & $9.1(2)$ & $0.0(0)$ \\
\hline \multicolumn{6}{|c|}{$\chi^{2}$-test $: \chi^{2}$-value $=29.0, d f=16, p=0.024$} \\
\hline
\end{tabular}




\section{R. NISHIHARA ET AL}

became angry after a small trigger and became irritated with high frequency than those who did not (Table 5). Students who regularly carried out a hair care regimen showed a significantly lower frequency of becoming angry after a small trigger and a lower frequency of losing control due to anger than those who did not (Table 6).

Table 5.

Relationship between whether or not they use perfume and mental health in Japanese women students aged 18 - 30 yrs. \% (n).

\begin{tabular}{|c|c|c|c|c|}
\hline \multirow[b]{2}{*}{ Perfume } & \multicolumn{4}{|c|}{ Frequency to feel depressed } \\
\hline & Often & Sometime & Rarely & Never \\
\hline Yes & $33.3(16)$ & $22.9(11)$ & $41.7(20)$ & $2.1(1)$ \\
\hline \multirow[t]{4}{*}{ No } & $18.4(21)$ & $41.2(47)$ & $36.0(41)$ & $4.4(5)$ \\
\hline & \multicolumn{3}{|c|}{$\chi^{2}$-test: $\chi^{2}$-value $=7.343, d f=3, p=0.062$} & \\
\hline & \multicolumn{4}{|c|}{ Frequency to feel anger after a small trigger } \\
\hline & Often & Sometime & Rarely & Never \\
\hline Yes & $14.6(7)$ & $10.4(5)$ & $54.2(26)$ & $20.8(10)$ \\
\hline \multirow[t]{4}{*}{ No } & $3.5(4)$ & $11.4(13)$ & $65.8(75)$ & $19.3(22)$ \\
\hline & \multicolumn{3}{|c|}{$\chi^{2}$-test $: \chi^{2}$-value $=6.903, d f=3, p=0.075$} & \\
\hline & \multicolumn{4}{|c|}{ Frequency to feel irritated } \\
\hline & Often & Sometime & Rarely & Never \\
\hline Yes & $22.9(11)$ & $16.7(8)$ & $50.0(24)$ & $10.4(5)$ \\
\hline \multirow[t]{4}{*}{ No } & $7.9(9)$ & $22.8(26)$ & $60.5(69)$ & $8.8(10)$ \\
\hline & \multicolumn{3}{|c|}{$\chi^{2}$-test: $\chi^{2}$-value $=7.531, d f=3, p=0.057$} & \\
\hline & \multicolumn{4}{|c|}{ Frequency to lose control due to anger } \\
\hline & Often & Sometime & Rarely & Never \\
\hline Yes & $0(0)$ & $2.1(1)$ & $33.3(16)$ & $64.6(31)$ \\
\hline \multirow[t]{2}{*}{ No } & $0(0)$ & $0.9(1)$ & $28.3(32)$ & $70.8(80)$ \\
\hline & \multicolumn{3}{|c|}{$\chi^{2}$-test: $\chi^{2}$-value $=0.60, d f=2, p=0.662$} & \\
\hline
\end{tabular}

Table 6.

Relationship between whether or not they carry out a hair care regimen and mental health in Japanese women students aged 18-30 yrs. \% (n).

\begin{tabular}{|c|c|c|c|c|}
\hline \multirow[b]{2}{*}{ Hair care } & \multicolumn{4}{|c|}{ Frequency to feel depressed } \\
\hline & Often & Sometime & Rarely & Never \\
\hline Yes & $21.9(28)$ & $35.2(45)$ & $40.6(52)$ & $2.3(3)$ \\
\hline \multirow[t]{4}{*}{ No } & $34.4(10)$ & $34.4(11)$ & $25.0(8)$ & $9.4(4)$ \\
\hline & \multicolumn{3}{|c|}{$\chi^{2}$-test $: \chi^{2}$-value $=5.403, d f=3, p=0.145$} & \\
\hline & \multicolumn{4}{|c|}{ Frequency to feel anger after a small trigger } \\
\hline & Often & Sometime & Rarely & Never \\
\hline Yes & $7.8(10)$ & $7.8(10)$ & $64.1(82)$ & $20.3(26)$ \\
\hline \multirow[t]{4}{*}{ No } & $3.1(1)$ & $28.1(9)$ & $56.3(18)$ & $12.5(4)$ \\
\hline & \multicolumn{3}{|c|}{$\chi^{2}$-test $: \chi^{2}$-value $=9.301, d f=3, p=0.026$} & \\
\hline & \multicolumn{3}{|c|}{ Frequency to feel irritated } & \\
\hline & Often & Sometime & Rarely & Never \\
\hline Yes & $13.3(17)$ & $20.3(26)$ & $58.6(75)$ & $7.8(10)$ \\
\hline \multirow[t]{4}{*}{ No } & $9.4(3)$ & $25.0(8)$ & $53.1(17)$ & $12.5(4)$ \\
\hline & \multicolumn{3}{|c|}{$\chi^{2}$-test: $\chi^{2}$-value $=1.312, d f=3, p=0.726$} & \\
\hline & \multicolumn{3}{|c|}{ Frequency to lose control due to anger } & \\
\hline & Often & Sometime & Rarely & Never \\
\hline Yes & $0(0)$ & $0.8(1)$ & $26.8(34)$ & $72.4(92)$ \\
\hline \multirow[t]{2}{*}{ No } & $3.1(1)$ & $3.1(1)$ & $43.8(14)$ & $50.0(16)$ \\
\hline & \multicolumn{3}{|c|}{$\chi^{2}$-test: $\chi^{2}$-value $=8.351, d f=3, p=0.039$} & \\
\hline
\end{tabular}




\section{Discussion}

For adult females, using makeup, perfume, or skincare products or carrying out a hair care regimen had no significant effect on circadian typology, and therefore does not appear to be a strong zeitgeber for the circadian clock system. Using such products does, however, appear to be potentially effective for improving sleep health in young women. Some chemical contained in makeup, perfume and skincare products, mechanical stimuli and/or psychological stimuli of these products may improve sleep quality in this case as well.

Twenty percent of the female students surveyed did not carry out a hair care regimen. Those students exhibited a mental state in which anger is more easily triggered than those who did carry out a hair care regimen. Moreover, the female students who used perfume tended to show higher frequency to be depressed, anger with a small trigger and irritated than those who did not. Hair care and the use of perfume may be related to stabilization of mental state in women, although this study has great limitation for such discussion and further experimental studies are required.

Makeup, perfume and skin care products might be possible to be related to better sleep health for students. Moreover, hair care and perfume may function as a stabilizer for the mental health in female students. Makeup, perfume and skin care products might be implied to become chemical, mechanical and/or psychological stimuli as effective agents for promoting sleep and mental health for young women students.

\section{Acknowledgements}

We thank all the participants of this study. Thanks are also due to the Kochi University President Foundation for Support of Research (2009-2012) and Research Fund by JSPS (Fund No: 22370089: 2010-2013) both to T. Harada.

\section{REFERENCES}

Borio, A, Heike, W., Karl, H., Joachim, T., \& Thomas, H. (2006). Chemosensory event-related potentials during sleep-A pilot study. Neuroscience Letters, 406, 222-226. doi:10.1016/j.neulet.2006.07.068

Goel, N., \& Lao, R. P. (2006). Sleep changes vary by odor perception in young adults. Biological Psychology, 71, 341-349. doi:10.1016/j.biopsycho.2005.07.004

Harada, T. (2008). Diurnal rhythm and sleep habit of Japanese infants, school children and university students-focusing on life environmental factors including factors related to $24 \mathrm{hrs}$ commercialization society. Chronobiology, 14, 36-43 (In Japanese).

Harada, T., Hirotani, M., Maeda, M., Nomura, H., \& Takeuchi, H. (2007). Correlation between breakfast tryptophan content and morningness-eveningness in Japanese infants and students aged 0 - $15 \mathrm{yrs}$. Journal of Physiological Anthropology, 26, 201-207.

Harada, T., Inoue, M., Takeuchi, H., Watanabe, N., Hamada, M., Kadota, G., \& Yamashita, Y. (1998). Study on diurnal rhythms in the life of Japanese university, junior high and elementary school students including morningness-eveningness preference. Bulletin of the Faculty of Education, Kochi University Series 1, 56, 1-91 (in Japa- nese). doi:10.1111/j.1479-8425.2003.00076.x

Harada, T., Kadowaki, A., Shinomiya, H., \& Takeuchi, H. (2004). Relationship between watching late night TV and morningnesseveningness of 18 - 22-year old Japanese students. Sleep and Biological Rhythms, 2, 97-98. doi:10.2114/jpa2.26.201

Harada, T., Morikuni, M., Yoshii, S., Yamashita.Y., \& Takeuchi, H. (2002). Usage of a mobile phone in the evening or at night makes Japanese students evening-typed and night sleep uncomfortable. Sleep and Hypnosis, 4, 150-154.

doi:10.1111/j.1479-8425.2006.00232.x

Harada, T., Tanoue, A., \& Takeuchi, H. (2006). Epidemiological studies on dream, sleep habits,mental symptoms in Japanese students aged $18-25$ y and $24 \mathrm{~h}$ commercialization of Japan society. Sleep and Biological Rhythms, 4, 274-281.

Horne, J. A. \& Östberg, O. (1976). A self assessment questionnaire to determine morningness-eveningness in human circadian rhythm. Chronobiology International, 4, 97-110.

Kato, T., Ishihara, S., \& Oki, M. (2010). Consciousness and behavior of make-up and their relationship to psychological health of Japanese women university students. Science Research on Living, 32, 81-89.

Komori, T., Tanida, M., Kikuchi, A., Shoji, K., Nakamura, S., Nomura, J. (1997). Effects of odorant inhalation on pentobarbital-induced sleep time in rats. Human Psychopharmacology, 12, 601-602. doi:10.1002/(SICI)1099-1077(199711/12)12:6<601::AID-HUP919> 3.0.CO;2-S

Krejci, M., Wada, K., Nakade, M., Takeuchi, H., Noji, T., \& Harada, T. (2011). Effects of videogame playing on the circadian typology and mental health of young Czech and Japanese children. Psychology, 2, 674-680. doi:10.4236/psych.2011.27103

Nagai, K. (2007). Mechanism of effects of two kinds of scents, one that makes humans obese and another that reduces weight-The importance of the circadian clock. Aroma Research, 3 (in Japanese).

Nakade, M., Takeuchi, H., Taniwaki, N., Noji, T., \& Harada, T. (2009). An integrated effect ofprotein intake at breakfast and morning exposure to sunlight on the circadian typology in Japanese infants aged 2 - 6 years. Journal of PhysiologicalAnthropology, 28, 239-245. doi:10.2114/jpa2.28.239

Ohmori, A., Shinomiya, K., Utsu, Y., Tokunaga, S., Hasegawa, Y., \& Kamei, C. (2007). Effect of santalol on the sleep-wake cycle in sleep-disturbed rats. Nihon Shinkei Seishin Yakurigaku Zasshi, 4, 167-171 (in Japanese with English Abstract).

Shinomiya, H., Takeuchi, H., Martoni, M., Natale, V., \& Harada, T. (2004). Comparative study on circadian typology of Japanese and Italian students aged 12 - 18 years. Sleep and Biological Rhythms, 2, 93-95. doi:10.1111/j.1479-8425.2003.00075.x

Takeuchi, H., Inoue, M., Watanabe, N., Yamashita. Y., Hamada, M., Kadota, G., \& Harada, T. (2001). Parental enforcement of bedtime during childhood results in Japanese junior high school students preferring morningness to eveningness. Chronobiology International, 18, 823-829. doi:10.1081/CBI-100107517

Takeuchi, H., Oishi, T., \& Harada, T. (2003). Morningness-eveningness preference, and mental and physical symptoms during the menstrual cycle of Japanese junior high school students. Sleep and Biological Rhythms, 1, 245-247. doi:10.1046/j.1446-9235.2003.00042.x

Torsvall, M. D., \& Åkerstedt, T. A. (1980). A diurnal type scale: Construction, consistency and validation in shift work. Scandinavian Journal of Work \& Environmental Health, 6, 283-290. doi: $10.5271 /$ sjweh. 2608

Wada, K., Krejci, M., Ohira, Y., Nakade, M., Takeuchi, H., \& Harada, T. (2009). Comparativestudy on circadian typology and sleep habits of Japanese and Czech infants aged 0 - 8years. Sleep and Biological Rhythms, 7, 218-221. 